\title{
The shape of the apparent visual world in darkness
}

\author{
LEONARD BROSGOLE and PAUL ULATOWSKI \\ St. John's University, Jamaica, New York 11439
}

\begin{abstract}
When deprived of light, a phenomenal field continues to endure in darkness. The vertical and horizontal extent of that field was measured monocularly and binocularly. In both instances, the field was found to be elliptical, i.e., greater horizontally than vertically. It was contended that these findings reflected the presence of a perceptual field in total darkness, because a control group, responding on a purely cognitive basis, indicated that the monocular field was circular and the binocular field was severely elliptical.
\end{abstract}

Although deprived of light in total darkness, we are certainly not devoid of visual experience. The world of darkness is a strange and fascinating one, so much so that it often evokes fear in the naive observer. It has many qualities, including distortion of depth, changes in shading and texture of the field that lead to an increasing inhomogeneity, the appearance of phosphenes, and the emergence of quite visible rings around the eyes which coincide with the ocular orbits. These phenomena have been described in great detail by Brosgole and Neylon (1973) and Hofstetter (1970).

Our visual experience not only has quality and character in the absence of light, but it also seems to have limits. Its extensity appears to be restricted by the quite evident orbits of the eyes. One thing is for certain, namely, the world in front is not the same as it is behind, above, or below us. Thus, the world before us would seem to have contour or shape. Accordingly, the purpose of this study was to map the shape of the phenomenal visual field in total darkness.

\section{METHOD}

\section{General}

Perimetry was used to map the field laterally, as well as vertically, in total darkness. As the reader may well imagine, the nature of this study gave rise to many problems. The first concern was how to map the apparent field in the absence of retinal stimulation and, hence, without using a visual target. This was resolved by permitting the subject to adjust a tactual target along the perimeter, using the method of average error. The second issue revolved around the instructions given to the subject, namely, where to position the target on the perimeter. It was decided to tell the subject to slide the target from the center outward, on ascending trials, until the target seemed to leave the darkened field in front to enter into the void behind. The target was positioned in the void on descending trials and adjusted until it just entered the darkened field.

The final problem dealt with the use of an appropriate control, for it was feared that any data could be interpreted as representing nothing more than a cognitive transfer of responses from lighted situations into darkness. In other words, it could be argued that perimetry in darkness could not be used to reflect the presence and shape of a perceptual field. Thus, two controls were used. The first control was to place a patch over the nondominant eye and map the monocular field of the dominant eye both vertically and horizontally. Now, imagine the absurdity of patching an eye in darkness. Yet, it was felt that, if the subjects were responding in purely cognitive terms, then any verticalhorizontal difference found binocularly should have diminished monocularly. On the other hand, a vertical-horizontal difference should have persisted if the subjects were, indeed, responding to a perceptual field. In addition, a separate control group was run in an attempt to obtain pure cognitive responses. This group was run in a lighted situation, with the subjects tested in pairs. One subject was seated with eyes closed and the head positioned in the perimeter. The second person adjusted the target from the center outward, on ascending trials, until it was believed to leave the field of the seated partner, i.e., if he or she were able to see. On descending trials the target was adjusted until it was believed to just enter the field. Again, there was vertical and horizontal mapping both monocularly and binocularly. Once the procedure was completed, the partners switched seats and the other person was tested.

In summary, the fields were mapped vertically and horizontally both monocularly and binocularly. These served as within-subject variables. Separate groups were tested, one in darkness (Group 1) and the other in a lighted situation (Group 2). This was a between-subject factor. Thus, a split-plot factorial design was appropriate for the analysis of the ensuing data.

\section{Subjects}

Eight males and eight females participated in this study. They were all undergraduate students who were naive as to the purpose of the study.

\section{Apparatus}

A Bausch and Lomb perimeter (Model 71-57-13) was used. The chinrest portion of the perimeter was modified so that the center of the perimeter was directly aligned with the nasion of the subject. Accordingly, all measurements were taken with reference to the nasion. The perimeter was located on a Bausch and Lomb instrument table. All testing took place in a light-tight chamber.

\section{Procedure}

Testing proceeded in total darkness for Group 1. The subject adjusted the slide on the perimeter with the index finger of the preferred hand placed in the indenture that would normally house a visual target. The assistance of the experimenter was required in adjusting the slide because of friction. There were 24 trials binocularly and 24 monocularly. Binocular testing was first for half the subjects and last for the remaining half. The limit of the upper, lower, left and right field was ascertained. There were three ascending and three descending trials at each limit. The order of testing each quadrant was randomized over trials. 
Group 2 was run in the same fashion except that assistance was not needed in adjusting the slide.

\section{RESULTS AND DISCUSSION}

Upper and lower limits were combined to obtain the extent of the vertical field. Similarly, the horizontal field was obtained by combining the left and right adjustments. For monocular viewing, Group 1 had a vertical field of $98.7 \mathrm{deg}$, compared to $119.8 \mathrm{deg}$ horizontally. Both fields expanded binocularly, with the vertical at 110.4 and the horizontal at $146.1 \mathrm{deg}$. For Group 2, the monocular field was $95.8 \mathrm{deg}$ vertically and $111.5 \mathrm{deg}$ horizontally. Their binocular field was $101.6 \mathrm{deg}$ vertically and 154.6 deg horizontally. These data were subjected to a split-plot factorial analysis of variance, with two within-subject and one between-subject factor.

There was a significant three-way interaction $(\mathrm{F}=5.13$, $\mathrm{df}=1 / 14, \mathrm{p}<.05)$. Subsequent simple effects indicated that a change from monocular to binocular viewing had no effect upon the judgment of the vertical extent in both groups. However, binocular viewing produced a significant increase in the horizontal extent for Group 1 $(\mathrm{F}=7.2, \mathrm{df}=1 / 28, \mathrm{p}<.05)$ and binocular observation $(F=20.5, \mathrm{df}=1 / 28, \mathrm{p}<.01)$. However, there was. no vertical-horizontal difference monocularly for Group 2 $(F=3.97, \mathrm{df}=1 / 28)$. The only difference found for that group was under binocular inspection $(F=45.4$, $\mathrm{df}=1 / 28, \mathrm{p}<.01)$.
The data can be expressed differently to more clearly illustrate the findings. The vertical may be taken as a proportion of the horizontal extent. In this instance, a proportion of .83 was found monocularly for Group 1 , compared to .76 binocularly. Since the above analysis indicated a significant vertical-horizontal difference in each case, we may conclude that the field in darkness was elliptical regardless of the condition of viewing. For the control, however, there was no difference monocularly and the obtained proportion of .91 may be construed as representing a circular field. Of course, there was a vertical-horizontal difference for this group binocularly, and the obtained proportion of .66 may be said to represent a highly elliptical cognitive field.

In conclusion, perimetry indicated that the shape of the apparent visual field in darkness is elliptical under both monocular and binocular observation. The subjects seemed to be responding to the presence of a perceptual field in darkness, because on a purely cognitive level, the field became circular monocularly and the ellipse was highly exaggerated binocularly.

\section{REFERENCES}

Brosgole, L., \& Neylon, A. Kinetic visual imagery. Perceptual and Motor Skills, 1973, 37, 423-425.

Hofstetter, H. W. Some observations on phantom visual imagery. American Journal of Optometry and Archives of American Academy of Optometry, 1970, 47, 361-366.

(Received for publication June 14, 1976.) 